DOI: http://dx.doi.org/10.20435/727

\title{
Do empoderamento ao desempoderamento: o indivíduo como protagonista do desenvolvimento local
}

\begin{abstract}
From empowerment to disempowerment: the individual as the protagonist of the local development
\end{abstract}

Thayliny Zardo ${ }^{1}$

Arlinda Cantero Dorsa ${ }^{2}$

${ }^{1}$ Mestre em Desenvolvimento Local - Universidade Católica Dom Bosco. Advogada. Pesquisadora. E-mail: thay_zardo@hotmail.com

${ }^{2}$ Doutora em Língua Portuguesa, Áreas de atuação: linguagens. Cultura. Diversidade. Professora Titular e Pesquisadora Universidade Católica Dom Bosco. E-mail: acdorsa@uol.com.br 


\section{RESUMO ABSTRACT}

A presente pesquisa é fruto de reflexões oriundas de revisão bibliográfica acerca da formação pessoal e social da pessoa humana, do desenvolvimento local e do empoderamento e desempoderamento do ser humano e relaciona-se ao Grupo de pesquisa em Patrimônio Cultural, Direito e Diversidades. Tem como objetivo desenvolver um estudo de natureza teórica, situando a origem dos termos e as perspectivas diversas ligadas às ações empoderadoras e desempoderadoras, de modo que a conclusão do estudo recai sobre a importância do (des) empoderamento do indivíduo ao processo desenvolvimentista, com ações positivas e/ ou negativas ao desenvolvimento social, familiar e educacional de grupos ou indivíduos engajados na melhoria do nível de qualidade de vida.

\section{PALAVRAS-CHAVE}

empoderamento participação desenvolvimento
This research results from reflections of the personal and social human person development from the literature review, as weel of local development and empowerment and disempowerment of human and relates to the Research Group on Cultural Heritage Law and Diversities. It aims to develop a study of a theoretical nature, placing the origin of the terms and the different perspectives related to empowering actions and desempoderadoras, so that the conclusion of the study is on the importance of (dis) empowerment of the individual to the development process, with actions positive and / or negative social development, family and educational groups or individuals engaged in improving the level of quality of life.

\section{KEY WORDS}

empowerment

participation

development 


\section{CONSIDERAÇÕES INICIAIS}

A família representa um dos grupos de socialização humana mais importantes, responsável por ensinar aos indivíduos as primeiras e mais diversas experiências, desde a fala e movimentação até crenças e valores imateriais, necessários à vivência social. De um outro modo, a estrutura familiar consiste na base de formação da identidade e personalidade das pessoas, as quais comporão a comunidade. Isto é, a família não é somente geradora, mas também preparadora de capital humano, do qual depende a constituição da teia social.

Aliado ao grupo familiar na tarefa de formação do ser humano, tem-se a sociedade, que transfere normas, padrões morais, éticos e culturais aos indivíduos, nas relações entre os pares. É na sociedade que se verifica a cooperação e a própria competição entre os seres, por exemplo, justificando-se a relevância social para a constituição da identidade humana.

Importante observar que tanto a família como a sociedade preparam o indivíduo para a vida em comunidade, ou seja, o ponto central de atenção é a pessoa humana. É a pessoa humana quem cuidará da sua própria história, bem como das transformações que entender necessárias ao seu bem-estar e qualidade de vida, com modificações ao ambiente à sua volta e a si mesmo, simultaneamente, engajando-se no processo desenvolvimentista, razão pela qual tem-se o ser humano como seu motor propulsor; que impulsiona e movimenta o desenvolvimento local, considerando-se a dimensão humana sua peça-chave.

\section{INDIVÍDUO: FORMAÇÃO PESSOAL E SOCIAL}

Todo ser humano, ao nascer, depende de cuidados e atenção especiais, os quais lhe são dados primeiramente pela família e posteriormente pela sociedade, seja por meio da escola e/ou 
das experiências vividas e compartilhadas com os indivíduos à sua volta. Isto é, "a vida relacional de um ser não pode depender só dele, porquanto toda relação verdadeira requer uma participação mútua" (BERGE, 1977). Trata-se da formação pessoal e social do indivíduo com vistas à sua socialização, esta entendida como o "processo de iniciação por meio do qual a criança pode desenvolver-se e expandir-se a fim de ingressar num mundo que está ao seu alcance" (BERGER; BERGER, 1977, p. 205).

Em tal contexto, Braga (1978, p. 211-212) aduz:

[...] deve se lembrar de que o que é mais importante para o desenvolvimento infantil é o relacionamento das crianças com as pessoas as cercam, [...]. Na vida de uma criança as pessoas proporcionam a base para o desenvolvimento de todas as suas aptidões; auxiliam seu relacionamento com as demais pessoas, e afetam a maneira pela qual ela virá a se sentir a seu próprio respeito, bem como influenciarão seu desenvolvimento de linguagem, cognitivo e outros. Qualquer que seja a sua idade, não é tão importante que a criança tenha brinquedos ou equipamentos: o que é essencial é que tenha pessoas que a apoiem, que dela cuidem, e que providenciem o que lhe for necessário para suprir as suas necessidades. Sintonizando-se bem com as suas crianças e compreendendo como elas se desenvolvem, você poderá se identificar com suas necessidades e dar-lhes atendimento.

A família representa o primeiro grupo de socialização dos indivíduos em que são construídas as bases iniciais da identidade humana, como preparo para a caminhada social. Todavia deve-se observar que a família, além de influenciar os indivíduos sociais, também sofre influências do meio a que pertence, sejam estruturas sociais, políticas e econômicas, e cujos reflexos recaem sobre cada pessoa do núcleo familiar, que os absorverá de forma diversa.

O que se tem é uma relação de causa e efeito (OSÓRIO, 1996) entre família e sociedade ou talvez uma espécie de sistema cíclico, em que a família forma o indivíduo, o qual comporá e relacionar-se-á com a sociedade, e esta, por sua vez, agirá sobre a família, delimitando comportamentos, regras, costumes e valores. 
Do empoderamento ao desempoderamento: o indivíduo como protagonista do desenvolvimento local

A entidade familiar, matriz social, geradora e formadora de agentes sociais, desempenha a função de ensinar aos seus entes os valores imateriais básicos sociais, necessários à constituição de sua personalidade como membro integrante da sociedade. No entendimento de Osório (1996, p. 20-21):

Esquematicamente poderíamos dividir as funções da família em biológicas, psicológicas e sociais; [...], já que estão intimamente relacionadas e confundem-se umas com as outras, tanto nas origens como no destino das estruturas familiares ao longo do processo civilizatório. [...]. Em resumo, a função biológica da família é a de garantir não a reprodução e sim a sobrevivência da espécie através dos cuidados ministrados aos recém-nascidos. $\mathrm{E}$ as funções psicossociais, quais seriam? Sabe-se que o alimento afetivo é tão indispensável para a sobrevivência do ser humano quanto o são o oxigênio que respira ou a água e os nutrientes orgânicos que ingere. Sem o afeto ministrado pelos pais ou os seus sub-rogados, o ser humano não desabrocha, permanece fechado em uma espécie de concha psíquica, caracterizando o estado de enquistamento emocional que denominamos autismo. [...]. Entre as funções sociais da família, por sua relevância ao longo do processo civilizatório, está a transmissão das pautas culturais dos agrupamentos étnicos. Outra das importantes funções sociais da família, e que a ela é delegada pela sociedade, é a preparação para o exercício da cidadania.

A família, para Osório (1996), deve fornecer substratos suficientes para o crescimento individual de seus membros, de maneira a facilitar a individuação e diferenciação de cada pessoa tanto na esfera familiar, como na esfera social, cujos requisitos são essenciais para um satisfatório convívio em sociedade. Trata-se da função social da família, em que ela assimila e amolda-se às transformações e evoluções sociais, transferindo aos seus novos membros todos os princípios necessários à sobrevivência no corpo social.

Nota-se ainda que, como a família, a sociedade também auxilia e influencia a solidificação da identidade e dos valores incorporados à personalidade do indivíduo. Depois de postos os 
alicerces iniciais para o caráter individual do ser humano e os valores imateriais básicos para o convívio inicial com a sociedade, a criança/adolescente começará a estabelecer contato com as demais pessoas, fora do vínculo familiar, como ocorre na fase escolar. Em suas relações sociais, a criança/adolescente faz uso de todo o conjunto de valores que adquiriu na família, como a cultura e o respeito ao outro, bem como adiciona outros que lhes pareçam novos.

A sociedade, por seu turno, é composta por regras, crenças, costumes e padrões. Por mais singulares que sejam os agentes sociais, toda a sociedade apresenta certa homogeneidade, uma coletividade exclusiva, que tem traços específicos que as tornam únicas, distintas umas das outras. Nesse sentido, todo novo indivíduo depara-se com um conjunto de normas e valores sociais e culturais, como norteadores de suas ações, atividades, comportamentos e delimitação de seus direitos e deveres. Trata-se de uma forma de preservar a unidade social e a identidade coletiva, a fim de que não se percam os ideais comuns e a luta pelo bem-estar social.

Por tal motivo, Bee (1996) assevera acerca da importância dos relacionamentos verticais e horizontais para o desenvolvimento humano. 0 relacionamento vertical é marcado pelo apego a uma pessoa, como ocorre com os pais, e cujo resultado é a sensação de segurança e proteção que a criança sente. Já o relacionamento horizontal se caracteriza pela reciprocidade e igualdade, com os colegas da escola por exemplo, quando "a criança pratica seu comportamento social e adquire aquelas habilidades sociais que só podem ser apreendidas num relacionamento entre iguais: cooperação, competição, intimidade" (BEE, 1996, p. 312).

Esse pensamento corrobora-se com o posicionamento de Souza $(1997,1997$, p. 66) ao discorrer sobre Bakhtin:

Para esse autor, ser significa ser para o outro e, por meio do outro, para si próprio. 0 território interno de cada um não é soberano; 
é com o olhar do outro que nos comunicamos com nosso próprio interior. Tudo que diz respeito a mim, assegura Bakhtin, chega à minha consciência por meio da palavra dos outros, com sua entoação valorativa e emocional. Do mesmo modo que o corpo da criança, inicialmente, forma-se do interior do corpo da mãe, a consciência do homem desperta a si própria envolvida na consciência alheia.

0 indivíduo, centro de transmissão de poder, por quem atravessam e circulam as relações de poder, internaliza os aspectos advindos da relação com seu semelhante, adaptando-os e incorporando-os à sua identidade. A "internalização é o processo pelo qual a experiência externa, culturalmente organizada, é transformada em processos psicológicos internos que, por sua vez, determinam a maneira como as pessoas se comportam" (COLE; COLE, 2004, p. 414). Esse processo é de suma importância para a aceitação da criança pela sociedade, pois é por meio dela que o infante demonstra o seu desejo e sua capacidade de se portar socialmente como a coletividade a que pertence.

Reflete-se que enquanto a família prepara o indivíduo para a vida social, a sociedade socializa-o. Os padrões socialmente impostos servem como modelo para as condutas individuais dos novos membros, de forma que o indivíduo apenas se faz reconhecido e participante da sociedade se aderir aos moldes que lhes foram postos. Todavia não se pode esquecer que o próprio processo de socialização é relativo e recíproco, em razão da existência não somente do socializado, como também do socializante, além da capacidade de escolha que os indivíduos carregam em si.

Gradativamente, a criança/adolescente é cada vez mais aceita (o) socialmente, e a ela (e) passam a ser atribuídas funções e papéis, bem como lhe é permitida certa liberdade de escolha frente a situações rotineiras. Pouco a pouco, esse infante começa a reproduzir as normas e comandos sociais que lhes foram impostos inicialmente, como resultado da socialização absorvida, ou seja, o que era estranho ao mundo interno do indivíduo passa 
a fazer parte dele a ponto de ser exteriorizado para aqueles que estiverem à sua volta.

Com a internalização das normas e padrões sociais, tem-se a progressão da socialização, cujo resultado é a formação da consciência individual. É nesse momento em que a criança/adolescente se vê como ser social e passa a reproduzir naturalmente todo esse conjunto de valores, bem como a exigir dos demais que ajam da mesma maneira.

A consciência individual, constituída pela sociedade, possibilita que a criança/adolescente atribua significados e símbolos aos comandos sociais com os quais lida. Ela (e) começa a ser sujeito ativo na vivência social, tornando-se um indivíduo singular para a sociedade como confirmação às "relações de interdependência entre indivíduo e sociedade" (SETTON, 2005, p. 342). De modo simplificado, o indivíduo passa a ser peça importante de que depende o processo desenvolvimentista, em busca de melhorias na qualidade de vida humana.

\section{DESENVOLVIMENTO LOCAL: UMA REFLEXÃO SOBRE OS ASPECTOS CONCEITUAIS}

O desenvolvimento local é um fenômeno que apenas se torna possível diante de características essenciais preexistentes, as quais são articuladas pela ação humana e voltadas a promover o desabrochamento das habilidades e potencialidades de determinada comunidade. Sobre o assunto, discorre Gonzalez (1998, p. 9) ao afirmar que "el D.L. persigue un objetivo básico y primordial: MEJORAR EL NIVEL DE VIDA DE LA POBLACIÓN, a partir de la combinación eficiente de las potencialidades de cada territorio, de sus recursos y de su fuerza emprendedora."

0 termo desenvolvimento local, ora denominado DL, ainda não possui um conceito específico, para tanto, entende-se que o conceito delineado abaixo seria o mais adequado à presente pesquisa: 
[...] el proceso reactivador de la economía y dinamizador de la sociedad local, mediante el aprovechamiento eficiente de los recursos endógenos existentes en una determinada zona, capaz de estimular y diversificar su crecimiento económico, crear empleo y mejorar la calidad de vida de la comunidad local, siendo el resultado de un compromisso por el que se entiende el espacio como lugar de solidaridad activa, lo que implica cambios de actitudes y comportamientos de grupos e individuos. (MARTÍN, 1999 apud ÁVILA, 2000, p. 68).

Amplia essa discussão Ávila (2000), quando pondera que no DL a comunidade passa a sentir mudanças significativas, pois:

[...] a comunidade mesma desabrocha suas capacidades, competências e habilidades de agenciamento e gestão das próprias condições e qualidade de vida, "metabolizando" comunitariamente as participações efetivamente contributivas de quaisquer agentes externos. (ÁVILA, 2000, p. 69).

O DL consiste, portanto, em um fenômeno de ativação de diversos elementos, tais como o território, a identidade e ações locais. Isso significa afirmar que é preciso a presença de uma comunidade (entendida como a presença de vínculos espontâneos entre as pessoas, com expectativas e experiências comuns, capazes de mantê-las unidas na vivência do cotidiano), situada em determinado território, com sua identidade social e histórica bem definida, de modo que seus próprios agentes atuam na solução de problemas, satisfação de necessidades, absorção de investimentos externos e busca pela qualidade de vida de todo o conjunto.

O DL também é social como o ser humano e, por tal motivo, ambos necessitam de um espaço para a execução de ações existenciais e de sobrevivência, na construção de histórias individuais tanto como da história coletiva. Assim, Santos (1978) aduz que o espaço pode ter uma concepção geográfica ou uma concepção social. Em sua concepção geográfica, o espaço é organizado pelo homem, durante a vivência social, tendo-se uma associação entre materialidade e ação humana em certo momento histórico. Por sua vez, o espaço social representa o lugar de vida do homem, 
sua morada, o espaço humano. Observa-se que "o espaço deve ser um conjunto indissociável de que participam de um lado, certo arranjo de objetos geográficos, objetos naturais, e objetos sociais, e, de outro, a vida que a preenche e os anima, ou seja, a sociedade em movimento" (SANTOS, 1994, p.49).

O espaço de que depende o DL deve ser definido, concreto, certo, apto a representar a realidade humana, uma vez que ele é produto da relação dos homens entre si e com os objetos à volta, simultaneamente. É o espaço que permite a interação humana e a construção espacial individual de acordo com as atividades e ações exercidas pelos indivíduos, atentando-se aos interesses coletivos e/ou pessoais. Em outras palavras, o espaço é o fruto da relação humana com os objetos e serviços em redor, suscetível de modificações de acordo com a evolução temporal e o surgimento de elementos transformadores.

A ideia de espaço deu azo a novos elementos caracterizadores do DL, quais sejam o território e a territorialidade. Os termos território e territorialidade associam-se às relações de poder (RAFFESTIN, 1993). Consoante o autor, o ser humano acaba por constituir um território quando domina e/ou se apropria de uma área, ali exercendo suas ações e trabalhos, de modo que cada território é marcado pela multidimensionalidade de vivências dos atores sociais na construção de sua territorialidade. Para o autor, o poder é envolvido por essa multidimensionalidade, representando "[...] a chave - em toda relação circula o poder que não é nem possuído nem adquirido, mas simplesmente exercido" (RAFFESTIN, 1993, p. 1).

0 mesmo entendimento é o de Haesbaert (2004, p. 3), pois esses elementos carregam "a multiplicidade de suas manifestações - que é também e, sobretudo, multiplicidade de poderes, neles incorporados através dos múltiplos sujeitos envolvidos".

Denota-se, então, que território e territorialidade basicamente representam uma reinvenção do espaço por parte dos 
Do empoderamento ao desempoderamento: o indivíduo como protagonista do desenvolvimento local

atores sociais que o ocupam como construção da base física para a comunidade. 0 espaço social modela-se, modifica-se e ajusta-se pelo território, ao mesmo tempo em que a territorialidade influi, delimita e controla-o. Desse modo, ambos os elementos revelam a identidade dos agentes locais, independentemente de se tratar de pessoas, grupos, empresas ou do próprio Estado, por exemplo, alterando-se de acordo com o controle social exercido por cada um com vistas a formar uma comunidade.

Concebidos o espaço, o território e territorialidade, os atores sociais deverão fortalecer, conjuntamente, os laços endógenos e exógenos, para que a comunidade possa usufruir tanto de suas forças internas, quanto das forças externas que sobre ela agem, na promoção do DL. O fortalecimento dos laços endógenos e exógenos é compreendido por Ávila (2000, p. 70) como a soma e a interação estratégica e necessária, visto que "a primeira sem a segunda se afiguraria a mera 'caiação desenvolvimentista' [...] e a segunda sem a primeira funcionaria como mecanismo de puro isolamento societário".

Os fatores endógenos consistem nas capacidades e forças internas de determinada comunidade, seja implícita ou explicitamente, capazes de promover o crescimento coletivo, tais como interesses comuns, funções individualizadas e cultura. Os fatores exógenos, por sua vez, compreendem o que é externo à comunidade, seja positivo ou negativo, capaz de contribuir, dificultar e/ ou limitar o progresso social, econômico e cultural, a exemplo do governo, das empresas, globalização etc.

Devem progredir ainda as relações primárias e secundárias na comunidade na promoção do DL. Não basta apenas a existência de vínculos espontâneos e informais entre pessoas na vivência do cotidiano (relações primárias), mas é necessário também que existam regras e normas formais para organizar e controlar os grupos sociais (relações secundárias) dentro da comunidade (ÁVILA, 2000). 
Tudo isso deve convergir para a formação de uma identidade local, caracterizada pelas atividades rotineiras realizadas pelos indivíduos e que são repletas de solidariedade. Por isso, cada lugar é singular, diverso um do outro, esculpidos pelo espaço, pelo tempo e pelos agentes que o ocupam, contendo uma dimensão histórica que permite a comunicação entre os homens por símbolos, vistos e sentidos uns pelos outros. A cognição e percepção do espaço ocupado melhoram a ponto de o ator social associar a ele uma dimensão simbólica e atribuir-lhe um significado mítico. Forma-se uma memória comunitária, como cenário social para as reuniões e práticas diárias.

Em que pese aos aspectos já delineados, nenhum deles teria sentido se não houvesse o capital social, a força propulsora do DL. Todavia essa união social depende da confiança entre seus semelhantes. Tabosa et al. (2004, p. 3) ensinam que "a confiança é a essência do capital social, sem ela, torna-se impossível uma sustentabilidade". Diante da desconfiança entre a comunidade, a tendência é que os membros sociais se dissociem uns dos outros, facilitando a existência de conflitos comunitários e dificultando o desabrochamento dos potenciais coletivos.

Em tal contexto, as redes sociais somente se originam quando há confiança recíproca entre os indivíduos. Quanto mais redes sociais se formarem e se fortalecerem, maior será o número de pessoas em busca de modificações e progressos para a comunidade a que pertencem. Por isso, é imprescindível que os indivíduos tenham em si valores éticos, morais e culturais a compartilhar com as demais pessoas à sua volta, em um processo contínuo de construção e reconstrução de identidades, com vistas a transparecer confiança e gerar solidariedade entre os pares.

Nas palavras de Tabosa et al. (2004, p. 6):

[...] deve-se enfatizar hoje a importância de desenvolver na cultura de seu povo o espírito de coletividade e solidariedade para alcançar o desenvolvimento, valorizando a sociedade, cons- 
truindo ou fortalecendo o capital social, objetivando melhorias nas condições de vida das populações, empenhando as relações sociais no território.

Reflete-se, portanto, que o DL depende do envolvimento participativo e coletivo dos atores locais. A sinergia social apenas tem sentido se toda a comunidade estiver voltada para a melhoria do nível de qualidade de vida, justificando-se a importância de cada indivíduo para a coletividade. Em outras palavras, é a união social que promove a interligação de todos os aspectos caracterizadores do DL; serão os próprios agentes sociais locais que buscarão o bem-estar, o crescimento coletivo e condições dignas de vida.

\section{0 (DES) EMPODERAMENTO DO INDIVÍDUO NA CONSTRUÇÃO SOCIAL}

O DL abarca um conjunto de elementos que, associados, convergem para a ativação dos atores sociais na promoção de mudanças e melhorias da comunidade. Dessa forma, o capital social alimenta e movimenta o processo desenvolvimentista, considerando-se o ser humano o protagonista do DL. Para tanto, o ser humano deve "aprender a escrever a sua vida, como autor e como testemunha de sua história, isto é, biografar-se, existenciar-se, historicizar-se" (FREIRE, 1977, p. 4).

Em tal contexto, o (des) empoderamento do indivíduo na construção social é de suma importância, de modo a agir positiva ou negativamente na participação social em ações voltadas ao desabrochamento das potencialidades comunitárias.

0 termo empoderamento (empowerment) tem suas origens na cultura americana, em 1970, sob a influência dos movimentos sociais, como a luta feminista e dos negros por direitos civis. $\mathrm{Na}$ referida época, o modelo tradicional de desenvolvimento apresentava sinais de colapso, tais como a marginalização do emprego na região urbana e o aumento da população sem terra, motivo 
pelo qual a palavra associava-se ao envolvimento participativo das pessoas em busca de controle sobre recursos e organizações, como uma forma de desenvolvimento alternativo (VASCONCELOS, 2003).

Paulatinamente, o empoderamento foi ganhando espaço e demais conceituações em diversas áreas, desde a sociologia, a psicologia até a saúde mental. Todavia importa à presente pesquisa aquelas que envolvem a capacidade individual de gerir a própria vida e direcionar suas vivências comunitárias. Nesse sentido, Freire (1977) representa a autoria brasileira precursora do tema, ao tratar da relação opressor e oprimido em que o empoderamento pode ser entendido como a conquista da liberdade por parte daquele que estava subordinado econômica, física ou mentalmente a outrem.

No mesmo sentido de significação de empoderamento, tem-se Rappaport (1987, p. 121) ao aduzir que:

The concept suggests both individual determination over one's own life and democratic participation in the life of one's community, often through mediating structures such as schools, neighborhoods, churches, and other voluntary organizations. Empowerment conveys both a psychological sense of personal control or influence and a concern with actual social influence, political power, and legal rights. It is a multilevel construct applicable to individual citizens as well as to organizations and neighborhoods; it suggests the study of people in context. ${ }^{1}$

Pelo mesmo viés, Vasconcelos (2003, p. 20) conceituou empoderamento como "aumento do poder e autonomia pessoal e coletiva de indivíduos e grupos sociais nas relações interpessoais

\footnotetext{
${ }^{1} \mathrm{O}$ conceito sugere uma determinação individual tanto sobre a própria vida como a participação democrática na vida de uma comunidade, muitas vezes por meio de estruturas intermediárias, tais como escolas, bairros, igrejas e outras organizações voluntárias. Empoderamento transmite tanto um sentido psicológico de controle pessoal ou influência como uma preocupação com a influência social real, poder político, e os direitos legais. É uma construção multinível aplicável aos indivíduos cidadãos, bem como a organizações e bairros; sugere o estudo das pessoas no contexto (tradução nossa).
} 
Do empoderamento ao desempoderamento: o indivíduo como protagonista do desenvolvimento local

e institucionais, principalmente daqueles submetidos a relações de opressão, dominação e discriminação social".

Em tal perspectiva, é possível refletir que as conceituações apresentadas tendem para o sentido de que o empoderamento dota o indivíduo de autonomia e liberdade sobre si mesmo; faz o ser humano sentir-se sujeito de direitos e deveres, integrante de uma comunidade, como membro ativo. Favorece também a consciência individual, a qual permite o enfrentamento das situações cotidianas; que faz com que o ser humano se sinta emancipado para manejar seus esteios; livre para mudar o que lhe aprouver em sua vida, por exemplo.

Observa-se ainda que o próprio termo empoderamento sugere a ideia de poder (TEIXEIRA, 2002), pois o indivíduo empoderado exerce o poder e direcionamento sobre a própria vida, desde aspectos pessoais até os políticos e econômicos com os quais se depara. Esse processo concede ao indivíduo o poder de gerenciar não somente a sua existência, como também as mudanças sociais que entender necessárias, uma vez que isso pode lhe afetar direta ou indiretamente, bem como pelo fato de que cabe aos atores sociais coordenarem as transformações que desejam ver na coletividade.

Em análise convergente, a comunidade também pode ser empoderada e exercer o controle sobre suas próprias experiências e tudo aquilo que lhe afeta. Teixeira (2002, p. 24) assevera que "o empoderamento está associado a formas alternativas de se trabalhar as realidades sociais, suporte mútuo, formas cooperativas, formas de democracia participativa, autogestão e movimentos sociais autônomos."

Silva e Martinéz (2004, s.p.) explicam que a comunidade empoderada "se baseia nos pontos fortes, habilidades e sistemas de apoio social que promovam a mudança nas comunidades". A coletividade, então, direciona-se para transformações locais, em busca da promoção do bem-estar social. 
A comunidade empoderada para Montero (2003 apud SILVA; MARTINÉZ, 2004, s.p.), consiste em um processo em que se tem o engajamento coletivo, consciente e crítico das pessoas, voltadas para o desenvolvimento das capacidades e recursos comunitários no controle de suas vidas, com o objetivo de transformar tanto a realidade vivida conforme as necessidades e aspirações coletivas, como a si mesmos ao mesmo tempo.

Diante dessa possibilidade de empoderamento comunitário, Kleba e Wendausen (2009, p. 733) explica que:

[...] o processo de empoderamento é apresentado a partir de dimensões da vida social em três níveis: psicológica ou individual; grupal ou organizacional; e estrutural ou política. 0 empoderamento pessoal possibilita a emancipação dos indivíduos, com aumento da autonomia e da liberdade. 0 nível grupal desencadeia respeito recíproco e apoio mútuo entre os membros do grupo, promovendo o sentimento de pertencimento, práticas solidárias e de reciprocidade. 0 empoderamento estrutural favorece e viabiliza o engajamento, a corresponsabilização e a participação social na perspectiva da cidadania. Compreende-se, no entanto, que a separação em níveis constitui-se em recurso didático e avaliativo, cujos componentes acontecem de modo interdependente, o que dificulta a separação entre processos e resultados. Os espaços de participação política constituem estruturas mediadoras de processos de empoderamento, facilitando a superação de conflitos e a re-significação das relações sociais, possibilitando a revisão de papéis e de sentidos na produção da vida cotidiana.

Nota-se que o empoderamento concede tanto ao indivíduo como à comunidade autodeterminação, autossuficiência e autonomia de controle sobre as experiências cotidianas. Ambos nutrem o sentimento de capacidade de decisão e administração dos seus percursos, com a visualização de existência e solução de problemas, bem como o desenvolvimento de estratégias para a melhoria das condições de vida. Os seres sociais empoderados observam as dificuldades e complicações presentes e lutam pela resolução, superação e o progresso dos incômodos, tal como objetiva o DL. 
Do empoderamento ao desempoderamento: o indivíduo como protagonista do desenvolvimento local

Nessa linha, o empoderamento acaba por promover o fortalecimento dos vínculos interpessoais. Individual e/ou coletivamente, os indivíduos formam uma consciência sobre a realidade vivenciada e tentam transformá-la para melhor com vistas a atingir o estado de bem-estar. Por essa razão, entende-se que o empoderamento do indivíduo é um elemento crucial ao DL, por meio do qual se ativa o ser humano para desenvolver o pensamento crítico sobre a vida e a sociedade, a consciência da realidade e a transformação daquilo que lhe distancia das condições dignas e satisfatórias de vida.

O termo desempoderamento, por sua vez, carrega o prefixo DES-, que somado ao adjetivo "empoderado", representa a ideia de contrariedade, negação, oposição ao sentido original da palavra. Para Cardoso (2006, p. 3), "o prefixo des- indica separação, transformação, intensidade, ação contrária, negação, privação". Desse modo, pretende-se aduzir que o desempoderamento consiste no processo reverso ao empoderamento. Se, no empoderamento, o ser humano sente-se detentor do direcionamento sobre a sua vida, no desempoderamento, o indivíduo não apresenta autoestima e autoconfiança em suas decisões, podendo ter dificuldades frente aos inconvenientes cotidianos. Sua capacidade crítica e de controle sobre sua situação pessoal e/ou social são frágeis e talvez inexistentes. É como se o indivíduo não se sentisse motivado a lidar com as experiências de sua vida ou não vislumbrasse razão para fazê-lo.

Reflete-se que, enquanto o empoderamento proporciona a autonomia sobre a própria vida, o desempoderamento ocasiona a sua perda e uma imagem negativa sobre a capacidade de transformação da realidade vivenciada. 0 indivíduo não vê em si mesmo habilidade para participar da dinâmica social, fazendo com que as interações com os seus semelhantes restem prejudicadas.

No desempoderamento, o indivíduo não sabe como agir diante dos problemas ou não tem coragem para colocar em prática o que acredita ser a solução. Diante de sua insegurança pessoal, 
permite que outras pessoas tomem a frente de sua vida e decidam por ele, de forma a perder a sua independência. Em outras palavras, o indivíduo desempoderado não se autorreconhece e/ ou autovaloriza como sujeito de direitos e obrigações, apto a desempenhar importantes funções sociais; ele se sente à margem da sociedade, sem qualquer influência ou poder social.

Para exemplificar o assunto, Teixeira (2002, p. 33) discorre sobre o desempoderamento em idosos:

[...] com a longevidade, há, geralmente, um processo de desempoderamento. Mudanças sociais nos modos de agir podem levar a uma perda de poder da autonomia e independência individual. Tipicamente, a interação de fatores individuais e sociais, na velhice, traz um ciclo negativo de desempoderamento, resultando na necessidade de reverter esse ciclo através do "re-empoderamento".

Observa-se que o desempoderamento representa uma espécie de esfacelamento comunitário. 0 indivíduo desempoderado não é ativo individual e coletivamente. Se ele não promove mudanças em sua vida, em busca de melhorias, no plano social também não verá sentido em fazê-lo. Nesse contexto, Baquero (2012, p. 179) ensina que "os indivíduos ou grupos relativamente desempoderados permanecem como objetos da relação, como os receptores da ação externa, numa atitude passiva", o que é de encontro à proposta de DL.

\section{CONSIDERAÇÕES FINAIS}

O Desenvolvimento Local tem como objetivo fazer do ser humano protagonista de sua história e de sua comunidade, com condições dignas de vida. Nessa proposta desenvolvimentista, a pessoa humana é responsável por promover as ações locais e transformar seu ambiente de vida, cujos valores imateriais necessários à formação pessoal e social do indivíduo, provém tanto da família como da sociedade em que está inserido. 
Reflete-se que a dimensão humana, portanto, é responsável por determinar o início, a continuidade e o fim do desenvolvimento. É a pessoa humana a força propulsora do DL; ela é quem detém o manejo e a capacidade de ativação de todos os demais elementos envolvidos no processo de transformação da realidade vivida, de sua comunidade. 0 ser humano é quem propõe e alcança a mobilização social, em que se tem o envolvimento coletivo e participativo dos indivíduos locais em busca do próprio bem-estar e de condições dignas e satisfatórias de vida para a comunidade a que pertence.

Importante observar que o desempoderamento do indivíduo impossibilita o regular desenvolvimento local. 0 indivíduo desempoderado é passivo aos estímulos externos, de modo que a dinâmica social resta prejudicada. 0 desempoderamento provoca a "coisificação" do ser humano, ou seja, torna o homem mero objeto nas relações sociais, devido à perda da sua independência $\mathrm{e}$ autonomia. Nesse viés, o indivíduo não se autorreconhece como detentor de direitos e deveres, não se autovaloriza como agente social, com pensamento crítico, consciência da realidade e influências e poder suficientes para realizar transformações ao meio em que se insere. A pessoa desempoderada não se sente integrada aos relacionamentos interpessoais e, por conseguinte, integrante de uma comunidade, motivo pelo qual não participa das ações e movimentos sociais em prol do bem-estar coletivo, em prol do desenvolvimento local.

A família, além de ser o primeiro e mais significativo núcleo socializador, em conjunto com a escola, incluindo-se a sociedade como um todo, devem se unir em combate ao desempoderamento do indivíduo, organizando-se para a prevenção do problema. Desenvolver ações em que esses indivíduos façam parte do processo decisório, principalmente nas situações que se refiram às próprias vidas; incentivá-los a sugerir ideias e opiniões, tendo em vista o desenvolvimento da capacidade crítica do ser humano; 
encorajá-los a participar de atividades conjuntas e sociais são algumas propostas que podem auxiliar no processo de empoderamento e, por conseguinte, no processo desenvolvimentista comunitário. Trata-se de uma tentativa de evitar que o problema se instale utilizando-se, indiretamente, estratégias de empoderamento em conformidade com o DL.

\section{REFERÊNCIAS}

ÁVILA, Vicente Fideles de. Pressupostos para formação educacional em desenvolvimento local. Interações - Revista internacional de Desenvolvimento Local, Campo Grande, MS, v. 1, n. 1, set. 2000. Disponível em: <http://site.ucdb.br/public/downloads/9083vol-1-n-1-set-2000.pdf>. Acesso em: 11 maio 2015.

BAQUERO, Rute Vivian Angel. Empoderamento: instrumento de emancipação social? - uma discussão conceitual. Revista Debates, Porto Alegre, RS, v. 6, n. 1, p. 173-187, jan./abr. 2012.

BEE, Helen. A criança em desenvolvimento. Tradução de Maria Adriana Veríssimo Veronese. 7. ed. Porto Alegre: Artes Médicas, 1996.

BERGE, André. A criança, hoje. Tradução de Teresa de Araújo Penna. Rio de Janeiro: Agir, 1977.

BERGER, Peter L.; BERGER, Brigitte. Socialização: como ser um membro da sociedade. In: FORACCHI, Marialice Mencarini; MARTINS, José de Souza. Sociologia e sociedade: leituras e introdução à sociologia. Rio de Janeiro: Livros Técnicos e Científicos, 1977. Disponível em: <http://pedagogia-uel.blogspot. com.br/2012/03/texto-01-de-sociologia-socializacao.html>. Acesso em: 20 abr. 2015.

BRAGA, Laurie. Aprendendo e crescendo. Tradução de Maria Elisa Mascarenhas. São Paulo: Saraiva, 1978.

CARDOSO, E. A. Os prefixos negativos: criação e expressividade na poesia de Drummond. Filologia e Lingüística Portuguesa, São Paulo, n. 8, p. 11-22, 2006. 
Do empoderamento ao desempoderamento: o indivíduo como protagonista do desenvolvimento local

COLE, Michael; COLE, Sheila R. O desenvolvimento da criança e do adolescente. Tradução de Magda França Lopes. 4. ed. Porto Alegre, RS: Artmed, 2004.

FREIRE, Paulo. Pedagogia do oprimido. 11. ed. Rio de Janeiro: Paz e Terra, 1977.

GONZALEZ, Román Rodrigues. La escala local del desarrollo - definición y aspectos teóricos. Revista de Desenvolvimento Econômico, Salvador, BA, ano 1, n. 1, 1998.

HAESBART, R. Dos múltiplos territórios à multiterritorialidade. Porto Alegre, RS, 2004. Disponível em: <http://www.ufrgs.br/ petgea/Artigo/rh.pdf>. Acesso em: 1o out. 2014.

KLEBA, Maria Elisabeth; WENDAUSEN, Agueda. Empoderamento: processo de fortalecimento dos sujeitos nos espaços de participação social e democratização política. Saúde e Sociedade, São Paulo, v. 18, n. 4, p. 733-743, 2009. Disponível em: <http:// www.scielo.br/pdf/sausoc/v18n4/16.pdf>. Acesso em: 14 maio 2015.

OSÓRIO, Luiz Carlos. Família hoje. Porto Alegre: Artes Médicas, 1996.

RAFFESTIN, Claude. Por uma geografia do poder. São Paulo: Ática, 1993.

RAPPAPORT, Julian. Terms of empowerment/exemplars of prevention: toward a theory for community psychology. American Journal of Community Psychology, v. 15, n. 2, 1987. Disponível em: <http://www.new-gallery-of-art.com/pdf/antioch/6.\%20 Rappaport\%20(1987).pdf>. Acesso em: 14 maio 2015.

SANTOS, Milton. Por uma geografia nova. São Paulo: Hucitec/ Edusp, 1978.

1994.

Metamorfoses do espaço habitado. 3. ed. São Paulo: Hucitec,

SETTON, Maria da Graça Jacintho. A particularidade do processo de socialização contemporâneo. Tempo Social, v. 17, n. 2, p. 335350, nov. 2005. 
SILVA, Carmen; MARTINEZ, María Loreto. Empoderamiento: proceso, nivel y contexto. Psykhe, Santiago, Chile, v. 13, n. 2, nov. 2004 . Disponível em: <http://www.scielo.cl/scielo. php?script=sci_arttext\&pid=S0718-22282004000200003\&lng= es\&nrm=iso>. Acesso em: 14 maio 2015.

SOUZA, Solange Jobim. Infância e linguagem: Bakhtin, Vygotsky e Benjamin. Campinas, SP: Papirus, 1997.

TABOSA, Francisco José Silva et al. A importância do capital social e da solidariedade para o desenvolvimento local: um estudo de caso. In: CONGRESSO DA SOCIEDADE BRASILEIRA DE ECONOMIA, ADMINISTRAÇÃO E SOCIOLOGIA RURAL-SOBER. 2004, 8p. Disponível em: <http://www.repositorio.ufc.br/bitstream/ riufc/5327/1/2004_eve_miomayorgaai.pdf>. Acesso em: 10 maio 2015.

TEIXEIRA, Mirna Barros. Empoderamento de idosos em grupos direcionados à promoção da saúde. 2002. 144f. Dissertação (Mestrado em Saúde Pública) - Escola Nacional de Saúde Pública da Fundação Oswaldo Cruz (FIOCRUZ), Rio de Janeiro, 2002.

VASCONCELOS, Eduardo Mourão. O poder que borta da dor e da opressão: empowerment, sua história, teorias e estratégias. São Paulo: Paulus, 2003. 